\title{
Chemical Stability of Mesoporous Oxide Thin Film Electrodes under Electrochemical Cycling: from Dissolution to Stabilization
}

\author{
Sebastián Alberti, ${ }^{\dagger}+$ Paula Y. Steinberg, ${ }^{\dagger}$ Gustavo Giménez, ${ }^{\S}$ Heinz Amenitsch, ${ }^{\|}$Gabriel Ybarra, ${ }^{\perp}$ \\ Omar Azzaroni, ${ }^{\ddagger}$ Paula C. Angelomé, ${ }^{\dagger}$ and Galo J. A. A. Soler-Illia*,\#(৫)
}

†Gerencia Química - Centro Atómico Constituyentes, Comisión Nacional de Energía Atómica, CONICET, Avenida General Paz 1499, 1650 San Martín, Buenos Aires, Argentina

${ }^{\ddagger}$ Instituto de Investigaciones Fisicoquímicas Teóricas y Aplicadas (INIFTA) - Universidad Nacional de La Plata - CONICET, CC 16 Suc. 4, 1900 La Plata, Buenos Aires, Argentina

${ }^{\S}$ Centro de Micro y Nanoelectrónica del Bicentenario, INTI-CMNB, Instituto Nacional de Tecnología Industrial, Avenida General Paz 5445, B1650WAB San Martín, Buenos Aires, Argentina

"Institute for Inorganic Chemistry, Graz University of Technology, Stremayrgasse 9/IV, 8010 Graz, Austria

${ }^{\perp}$ Unidad Técnica Nanomateriales, INTI-Procesos Superficiales, Instituto Nacional de Tecnología Industrial, Avenida General Paz 5445, B1650WAB San Martín, Buenos Aires, Argentina

\#Instituto de Nanosistemas, UNSAM, CONICET, Avenida 25 de Mayo 1021, 1650 San Martín, Buenos Aires, Argentina

Supporting Information

ABSTRACT: Mesoporous oxide thin films (MOTF) present very high surface areas and highly controlled monodisperse pores in the nanometer range. These features spurred their possible applications in separation membranes and permselective electrodes. However, their performance in real applications is limited by their reactivity. Here, we perform a basic study of the stability of MOTF toward dissolution in aqueous media using a variety of characterization techniques. In particular, we focus in their stability behavior under the influence of ionic strength, adsorption of electrochemical probes, and applied electrode

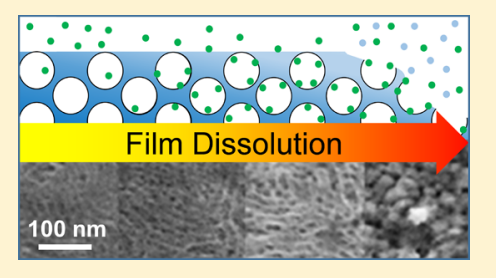
potential. Mesoporous silica thin films present a limited chemical stability after electrochemical cycling, particularly under high ionic strength, due to their high specific surface area and the interactions between the electrochemical probes and the surface. In contrast, $\mathrm{TiO}_{2}$ or $\mathrm{Si}_{0.9} \mathrm{Zr}_{0.1} \mathrm{O}_{2}$ matrices present higher stability; thus, they are an adequate alternative to produce accessible, sensitive, and robust permselective electrodes or membranes that perform under a wide variety of conditions.

\section{INTRODUCTION}

The interest in templated mesoporous materials has increased in the last decade due to their high suface area, regular porosity, and tailorable surface. These features have spurred their possible applications in sensors, solar cells, nanofluidic devices, catalysts, and medical applications, such as drug delivery devices, intelligent cell scaffolds, or bone regeneration. ${ }^{1}$ These materials are synthesized by sol-gel chemistry combined with supramolecular templates that self-assembly ${ }^{2,3}$ and allow the possibility of obtaining hard-soft intelligent nanosystems able to respond to external stimuli. ${ }^{4,5}$ While titania has received much attention for photovoltaic applications, catalysis and as bioinorganic interfaces because of its low toxicity and great stability, ${ }^{6-8}$ silica-based materials have been proven to be a convenient choice for drugs encapsulation and delivery. ${ }^{9}$ These outstanding and highly controllable features give mesoporous materials great relevance and potential in several fields of applications, particularly in analytical devices. $^{10,11}$

Mesoporous oxide thin films (MOTF) with a highly controlled pore architecture and functions in several length scales are currently produced through the combination of sol- gel and self-assembly techniques. ${ }^{12-14}$ These materials present high potential in sensing, ${ }^{14-16}$ molecular sieving, ${ }^{17}$ catalysis, ${ }^{18,19}$ or nanofluidic devices. ${ }^{20,21}$ In particular, MOTF can be deposited onto conductive substrates, leading to electrodes with highly tunable and robust inorganic architectures that ensure fast mass transport and a rapid response. ${ }^{1,16,22}$ In addition, there is nowadays a plethora of pore functionalization methods that permit binding of organic, polymeric, nanostructured, or biofunctional groups to the mesopores, which can impart a recognition ability, tuned reactivity or responsivity to the mesopore systems. ${ }^{5}$ Functional modified mesoporous thin film electrodes offer promise for analytical applications due to their specific properties such as high accessibility toward analytes, molecular sieving, preconcentration ability, and possible coupling with optical detection (plasmons, fluorescence, SERS, etc.). ${ }^{11,17}$ With its increasing importance, the understanding on MOTF fundamental chemical and structural

Received: January 24, 2019

Revised: April 12, 2019

Published: April 15, 2019 
stabilities has been put under consideration in order to achieve reproducibility and performance.

The stability of MOTF electrodes under operation conditions is one of the key factors to their use in real world analytical applications. ${ }^{10,16}$ While dissolution may be an advantage or a disadvantage depending on the goal of the device, the variables that are involved when the actual devices are in contact with an aqueous matrix (i.e., chemical composition, $\mathrm{pH}$, ionic strength, presence of complexing agents, applied voltage, etc.) must be carefully assessed. Recently, reports have dealt with the stability of mesoporous materials under operation, relevant for sorbents or catalysts, or under physiological conditions aimed at biological applications such as biomolecule separation, biosensing, prosthetics, or drug delivery. ${ }^{23}$ In this regard, it is well known that the dissolution of mesoporous silica is significant at alkaline $\mathrm{pH}$ or near neutral solutions; ${ }^{24}$ in addition, some insight into the role of the buffer identity on the dissolution of different silica nanoparticles has been gained. ${ }^{25}$ Nevertheless, there are few studies dealing with the stability of MOTF electrodes in conditions corresponding to sensor operation in solution, such as $\mathrm{pH}$ (particularly under acidic conditions) and ionic strength of the media, role of electrochemical probe adsorption, and electrochemical cycling, which are essential to the long-term device performance.

In this work, the chemical stability of MOTF in aqueous solutions that mimic sensing conditions was evaluated. For the first time, the susceptibility of silica, titania, and silica-zirconia MOTF to acidic conditions (between $\mathrm{pH} 3$ and 6) and the combined influence of this susceptibility to ionic strength, cycling voltage, and probes charge is reported. We find that silica film electrodes are labile to mildly acidic conditions, particularly at higher ionic strengths, and under electrochemical cycling, which precludes its use in long-term permselective electrodes. On the other hand, Zr-substituted silica or titania mesoporous thin films are robust enough to withstand the operation conditions that require contact with aqueous solutions and electrochemical solicitation.

\section{MATERIALS AND METHODS}

MOTF were prepared by dip- or spin-coating process, following previously reported routes. ${ }^{26-29} \mathrm{~A}$ mixture of absolute ethanol (EtOH, Biopack) and E-pure or Milli- $Q$ water $\left(R=18 \mathrm{M} \Omega \mathrm{cm}^{-1}\right)$ was used as the solvent. $\mathrm{HCl}$ (Merck) was used in order to control the hydrolysis and condensation of the inorganic species, Pluronic F127 triblock copolymer (Sigma-Aldrich) as the pore templating agent, and tetraethoxysilane (TEOS, Merck), $\mathrm{TiCl}_{4}$ (Sigma-Aldrich), or $\mathrm{ZrCl}_{4}$ (Sigma-Aldrich) as the oxide precursors. Nonmesoporous films were prepared in the same manner but in the absence of the structuring agent for comparison purposes.

Silica films were prepared from a sol of a molar ratio TEOS/EtOH/ $\mathrm{H}_{2} \mathrm{O} / \mathrm{HCl} / \mathrm{F} 127$ = 1:40:10:0.008:0.005, which was aged at room temperature for 3 days. Titania films were prepared from fresh solutions of a molar ratio $\mathrm{TiCl}_{4} / \mathrm{EtOH} / \mathrm{H}_{2} \mathrm{O} / \mathrm{F} 127=1: 40: 10: 0.005$. Mixed $\mathrm{Zr}$-Si oxides $\left(\mathrm{Si}_{0.9} \mathrm{Zr}_{0.1} \mathrm{O}_{2}\right)$ were prepared from a fresh sol of molar ratio $\mathrm{ZrCl}_{4} / \mathrm{TEOS} / \mathrm{EtOH} / \mathrm{H}_{2} \mathrm{O} / \mathrm{F} 127=0.1: 0.9: 40: 10: 0.005$.

In order to obtain mesoporous electrodes, the MOTF were deposited onto indium tin oxide covered glass (ITO, Delta Technologies, $R=8-12 \Omega \mathrm{sq}^{-1}$ ), sputtered gold electrodes ( $\mathrm{Ti} / \mathrm{Au}$ $10 / 100 \mathrm{~nm}$, Targets $3 \mathrm{~N}$ ) or on top of silicon wafers (University Wafer, Inc.). Films were deposited by dip-coating (withdrawal speed of $2 \mathrm{~mm} \mathrm{~s}^{-1}$, deposition performed at $30 \%$ relative humidity $(\mathrm{RH})$ ) or spin-coating $(4000 \mathrm{rpm})$ at room temperature. After the film drying, the RH was increased to $50 \%$ and held for $30 \mathrm{~min}$. After that period, films were treated at $60{ }^{\circ} \mathrm{C}$ for $30 \mathrm{~min}$ and at $130{ }^{\circ} \mathrm{C}$ for $30 \mathrm{~min}$.
Finally, the samples were calcined at $350{ }^{\circ} \mathrm{C}$ during $2 \mathrm{~h}$ using a thermal ramp of $1{ }^{\circ} \mathrm{C} \mathrm{min}^{-1}$. Removal of the organic structuring agent by calcination led to robust, ordered MOTF with monodisperse and accessible pores, adequately supported on conductive electrodes.

The chemical stability of the MOTF was studied by cyclic voltammetry $(\mathrm{CV})$ with a potentiostat/galvanostat TQ 03 (GQ-CACCNEA) in a three-electrode Teflon made cell using $\mathrm{Ag} / \mathrm{AgCl}(+0.197$ $\mathrm{V}$ vs NHE) $)^{30}$ as the reference electrode and the glassy carbon as the counter electrode. The measures were performed at different scan rates (from 50 to $300 \mathrm{mV} \mathrm{s}^{-1}$ ) using $\mathrm{KCl}$ (Merck) as the support electrolyte and in the presence or absence of ferricyanide $\left(\mathrm{K}_{3} \mathrm{Fe}\right.$ $(\mathrm{CN})_{6}$, Merck) or hexamine ruthenium (III) $\left(\mathrm{Ru}\left(\mathrm{NH}_{3}\right)_{6} \mathrm{Cl}_{3}\right.$, Acros) as electrochemically active probes. For this purpose, aqueous solutions were prepared with E-pure or Milli- $Q$ water $(R=18 \mathrm{M} \Omega$ $\left.\mathrm{cm}^{-1}\right), \mathrm{KCl}(0.1$ or $0.5 \mathrm{M})$, and an electrochemical active probe concentration of $1 \mathrm{mM}$. Basic and neutral $\mathrm{pH}$ influence has been reported elsewhere. ${ }^{23,31}$ In order to explore mildly acidic conditions, akin to natural waters, the interval between $\mathrm{pH} 3$ to 5.5 was tested, in all cases adjusted by adding $\mathrm{HCl}$ to the initial solutions. For the dissolution studies, a set of samples was immersed in the solutions mentioned above, while a second set was exposed to electrochemical cycling under the same $\mathrm{pH}$ and ionic strength.

MOTF samples were characterized at different stages of the chemical stability study by field emission scanning electron microscopy (FE-SEM) and environmental ellipsometric porosimetry (EEP). FE-SEM images were obtained with a Carl Zeiss NTS SUPRA 40 microscope (CMA, FCEyN, UBA). The samples were immobilized on an aluminum support with an adhesive carbon tape. EEP measures were obtained in a SOPRA GES5A equipment under a controlled relative vapor pressure of water $\left(P / P_{\mathrm{o}}\right)$ at room temperature $(298 \mathrm{~K})$. The experimental data was fitted by Winelli software using a Forouhi-Bloomer dispersion law for describing the optical properties of the $\mathrm{TiO}_{2}$ samples and a Cauchy model for the pure and substituted silica MOTF. The pore and neck size distributions were obtained from the adsorption-desorption isotherms using models based on the Kelvin equation. ${ }^{32}$ Water contact angle on the films was determined by using a Ramé-Hart 190 CA, with Ramé-Hart DROP image software for the drop shape analysis.

Grazing incidence small-angle X-ray scattering (GI-SAXS) patterns were acquired at the Austrian SAXS beamline at the Elettra synchrotron (Trieste, Italy), using a $1.54 \AA$ ( $8 \mathrm{keV})$ incidence X-ray beam. ${ }^{33}$ Samples were placed at $82.88 \mathrm{~cm}$ from a pixel detector (PILATUS $1 \mathrm{M}$ ) on a rotation stage, which allowed to set a glancing angle between the incident radiation and sample to $3^{\circ}$. Samples were prepared onto coverslips (about $0.15 \mathrm{~mm}$ thick) to allow measurements in Laue geometry. The angular scale of the detector was calibrated using Ag-behenate as the reference pattern.

Surface plasmon resonance (SPR) measurements were performed using linearly polarized monochromatic light from a $\mathrm{He}-\mathrm{Ne}$ laser (PL610P, Polytec, Germany, power of $2 \mathrm{~mW}$, wavelength $(\lambda)=632.8$ $\mathrm{nm})$. The polarized beam passed through a chopper (Princeton Applied Research, USA) for the lock-in detection and was coupled to a LASFN9 prism. Onto the prism base, a LASFN9 glass substrate with a $2 \mathrm{~nm}$ layer of $\mathrm{Cr}$ and a $50 \mathrm{~nm}$ thick layer of $\mathrm{Au}$ was optically matched using immersion oil (Cargile, USA). The intensity of the light beam reflected at the prism base was measured using a photodetector and a lock-in amplifier (model 5210, Princeton Applied Research, USA). The angle of incidence of the light beam was controlled using a rotation stage (Hans Huber AG, Germany). A flow cell consisting of a rubber $\mathrm{O}$-ring and a UV-transparent glass substrate was pressed against the mesoporous film on a gold surface to form a chamber with approximately $250 \mu \mathrm{L}$ volume. The measurements were done under the flow through inlet and outlet ports drilled to the glass substrate. For these measurements, the films were deposited onto Au. These Au substrates were prepared over LASFN9 glass substrates. Two nanometers of $\mathrm{Cr}$ and $50 \mathrm{~nm}$ of $\mathrm{Au}$ were deposited by vacuum thermal evaporation (HHV Auto 306 from HHV Ltd.) in vacuum lower than $10^{-6}$ mbar. 


\section{RESULTS AND DISCUSSION}

Transparent homogeneous crack-free $\mathrm{TiO}_{2}, \mathrm{SiO}_{2}$, and $\mathrm{Si}_{0.9} \mathrm{Zr}_{0.1} \mathrm{O}_{2}$ mesoporous thin films were synthesized on ITO and $\mathrm{Au}$ covered glass substrates by dip- or spin-coating, using the evaporation-induced self-assembly approach. ${ }^{2}$ The obtained thin films presented a high porosity (45 and 35\% for silica-based and titania thin films, respectively) with pore diameters of around $6 \mathrm{~nm}$. The thickness values for MOTF prepared under the described experimental conditions were in the range of 225-250 nm for $\mathrm{TiO}_{2}$ and $135-165 \mathrm{~nm}$ for $\mathrm{SiO}_{2}$; values for specific samples are provided in Table S1. Film reproducibility is high, although samples deposited on different substrates can present different thickness due to different geometries or substrate wetting properties. Differences in thickness in films from the same batch (within 5\%) can also arise due to minor changes in temperature or relative humidity during deposition or treatment steps. The structural evolution of the MOTF was followed by SEM, EEP, GI-SAXS, and SPR. While SEM and EEP were used to support and give a deeper insight into the films dissolution under electrochemical cycling; GI-SAXS, SEM, EEP, and SPR were used to study the dissolution in the absence of electrical potential.

Chemical Stability of Mesoporous Silica Electrodes. Mesoporous silica thin film electrodes were immersed in $1 \mathrm{mM}$ $\mathrm{Fe}(\mathrm{CN})_{6}{ }^{3 / 4-}$ or $\mathrm{Ru}\left(\mathrm{NH}_{3}\right)_{6}{ }^{3+}$ dissolved in $0.1 \mathrm{M} \mathrm{KCl}$ aqueous solution, or in $0.1 \mathrm{M}$ or $0.5 \mathrm{M} \mathrm{KCl}$ aqueous solution without any probe, at a $\mathrm{pH}$ of about 5 (nonregulated). FE-SEM and GI-SAXS measurements were performed on samples before immersion and withdrawn from each solution after aging for 24 and $48 \mathrm{~h}$. An example of the obtained GI-SAXS patterns before exposure is presented in the insets of Figure $1 \mathrm{a}, \mathrm{b}$ for the case of $\mathrm{Fe}(\mathrm{CN})_{6}{ }^{3-}$. These measurements showed that although some changes take place, the symmetry of the mesostructure (Im $3 \mathrm{~m}$ cubic combined with locally ordered $)^{28}$ was not significantly modified in the tested conditions. A decrease in the GI-SAXS signal intensity is also registered as a function of time, which can be attributed to a partial mesostructure degradation. The same samples were studied by EEP to analyze the porosity and pore/neck size distributions and by ellipsometry to obtain their thicknesses. MOTF samples present type IV isotherms with $\mathrm{H} 2$ loops; therefore, pore and neck diameters were obtained from the adsorption-desorption curves. ${ }^{34}$ After $48 \mathrm{~h}$ of exposure, the films' thicknesses decreased to about one third of their original value (see values in Table S1). Moreover, the pore volumes rose from $40 \%$ to $50-65 \%$, depending on the sample. Accordingly, both the average pore and neck diameters increase, and the pore size distribution becomes wider (Figure $1 \mathrm{c}-\mathrm{e}$ ). The aspect ratio (necks/pores) changes from 0.5 to 0.7 , therefore increasing the interpore connectivity. This behavior is in accordance to the partial degradation of the mesoporous structure observed in the film surface by SEM when comparing samples before and after exposure to $\mathrm{Fe}(\mathrm{CN})_{6}{ }^{3-}$ solution (Figure 1a,b).

From these preliminary long-term experiments, we can conclude that in silica films exposed to near neutral media, a partial dissolution takes place, reflected in a decrease of film thickness and an increase in porosity. The dissolution affects the interpore necks in higher proportion, increasing pore connectivity, and permitting an enhanced permeation. However, this process is significantly slower than in the case of mesoporous silica films exposed to conditions similar to
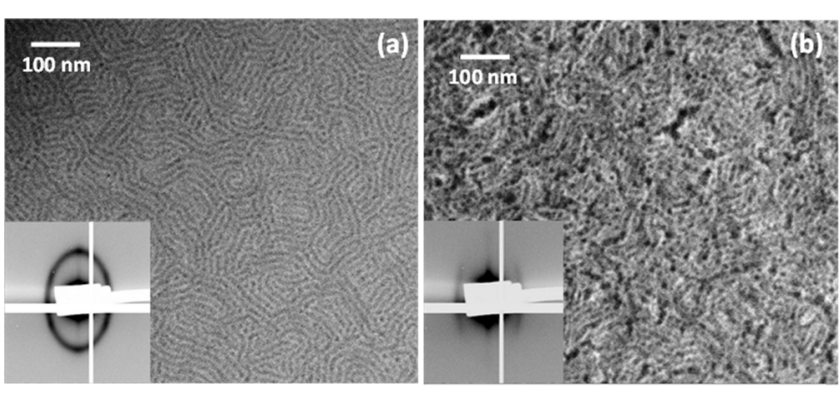

Pore radii / $\mathrm{nm}$

Pore radii / $\mathrm{nm}$

Pore radii $/ \mathrm{nm}$

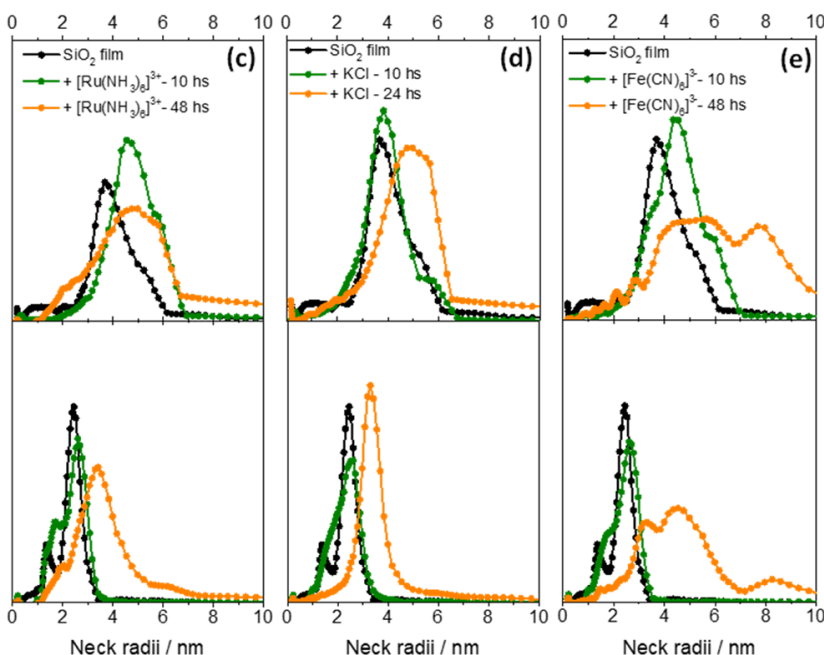

Figure 1. FE-SEM and GI-SAXS patterns of $\mathrm{SiO}_{2} \mathrm{MOTF}$ (a) before and (b) after immersion in $\mathrm{Fe}(\mathrm{CN})_{6}^{3-}(0.1 \mathrm{M} \mathrm{KCl})$ solution for $24 \mathrm{~h}$. Pore (upper) and neck (lower) diameters obtained by EEP for bare samples in comparison with samples in contact with (c) $\mathrm{Ru}\left(\mathrm{NH}_{3}\right)_{6}{ }^{3+}$ $(0.1 \mathrm{M} \mathrm{KCl})$, (d) $0.1 \mathrm{M} \mathrm{KCl}$, and (e) $\mathrm{Fe}(\mathrm{CN})_{6}{ }^{3-}(0.1 \mathrm{M} \mathrm{KCl})$.

biological media (i.e., $37^{\circ} \mathrm{C}, \mathrm{pH} 7.4$, presence of phosphate), in which films can dissolve in less than $120 \mathrm{~min}^{23}$

To gain an in-depth view of the dissolution process under a variety of experimental conditions, SPR measurements were performed in situ along $12 \mathrm{~h}$ for selected silica samples. The influence of the $\mathrm{pH}$, ionic strength, and identity of electrochemical probes was studied, using independent $\mathrm{SiO}_{2}$ films for each measure. Please note that SPR is a highly sensitive technique; a variation of 0.01 units in the film refractive index leads to a 1.13 degree difference in the SPR signal; therefore, the initial angle values might differ for different samples. However, a comparison of the signal changes along time provides valuable information in film dissolution. The minimum SPR signal was tracked along time; the evolution of the SPR angle shift is presented in Figure 2.

A decrease in the SPR angle value reflects the film deterioration for all the tested conditions. This behavior can be directly attributed to material loss due to both thickness and refractive index decrease. Because the SPR signal is not sensitive to processes that take place above $150 \mathrm{~nm}$ from the substrate, for samples with thickness larger than this upper limit, changes can be mainly attributed to variations of the refractive index. A decrease of two degrees in the minimum position for the plasmon resonance is roughly equivalent to a decrease of 0.02 units in the refractive index or analogously a decrease in the silica amount of $8 \%$ in volume fraction. Nevertheless, both thickness and refractive index diminishing occur, and both contribute to material loss. If the film thickness becomes lower than $150 \mathrm{~nm}$, the shift in the minimum angle 


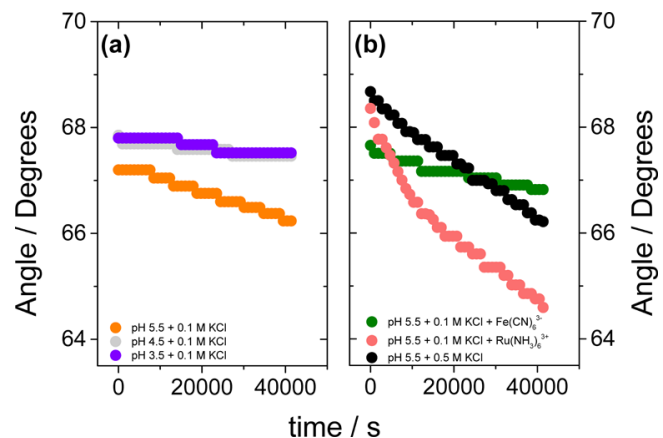

Figure 2. SPR minimum angle tracking through time (a) for different $\mathrm{pH}$ values and $(\mathrm{b})$ in the presence of different electrochemical probes or ionic strengths.

can be attributed to both processes, making hard to discriminate both contributions.

It is worth noticing that, in the results presented in Figure 2, a steady decrease in the SPR minimum angle can be consistently observed. At short times, this behavior can be mainly attributed for refractive index changes, due to the increase in the pore volume and pore size, indicating that not just a simple delamination from the substrate occurs. ${ }^{35}$

As it has been determined that mesoporous silica dissolution is significant near neutral $\mathrm{pH}$, the effect of $\mathrm{pH}$ was tested in detail in acidic media. Our experiments (Figure 2a) show that a decrease in the SPR, linked to an increase in the porosity of $\mathrm{SiO}_{2}$ MOTF takes place in the $\mathrm{pH}$ 3-5 range, when exposed to solutions with low ionic strength $(100 \mathrm{mM} \mathrm{KCl})$. In the case of dense silica thin films deposited on $\mathrm{Au}$, dissolution only took place in alkaline conditions. ${ }^{36}$ However, it is possible that the much more exposed mesoporous matrices present dissolution in mildly acidic conditions at a slower yet noticeable rate. Other factors can also aid this deleterious effect. For example, immersion of mesoporous silica thin films in $500 \mathrm{mM} \mathrm{KCl}$ shows a significant increase in the dissolution rate compared to a lower ionic strength media for the same $\mathrm{pH}$ (Figure 2b). ${ }^{37}$ Finally, the effect of the presence of electroactive ions in the dissolution rate was tested (Figure $2 b$ ). The addition of $\mathrm{Fe}(\mathrm{CN})_{6}{ }^{3-}$ does not imply major changes on the initial dissolution rate, its effect being comparable to the change in the ionic strength. On the other hand, the presence of $\mathrm{Ru}\left(\mathrm{NH}_{3}\right)_{6}{ }^{3+}$ speeds up the dissolution in a significant way. These effects suggest that the ion adsorption on the silica surface can assist silica dissolution, in particular, at early stages.

In order to study the influence of the electrode operation conditions, cyclic voltammetry experiments were performed over the $\mathrm{SiO}_{2}$ MOTF in the presence of $\mathrm{Fe}(\mathrm{CN})_{6}^{3-}$ and $\mathrm{Ru}\left(\mathrm{NH}_{3}\right)_{6}{ }^{3+}$ at $\mathrm{pH}=5.5$ and $[\mathrm{KCl}]=0.1 \mathrm{M}$ conditions, in which only a relatively slight dissolution was observed within
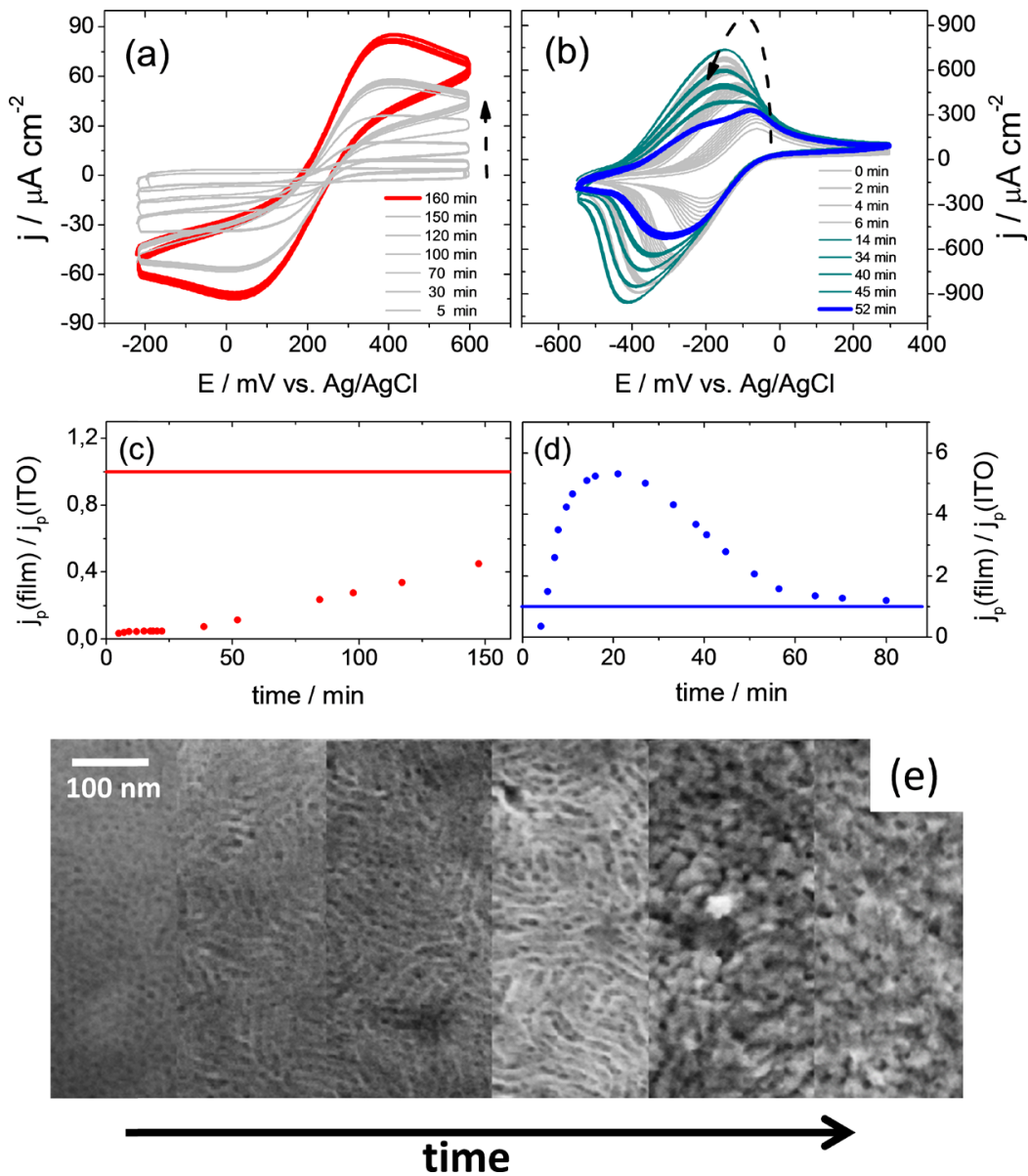

Figure 3. Voltammograms obtained at a scan rate of $300 \mathrm{mV} \cdot \mathrm{s}^{-1}$ for $\mathrm{SiO}_{2}$ MOTF immersed in (a) $1 \mathrm{mM} \mathrm{Fe}(\mathrm{CN})_{6}{ }^{3-}(0.1 \mathrm{M} \mathrm{KCl})$ and $(\mathrm{b}) 1 \mathrm{mM}$ $\mathrm{Ru}\left(\mathrm{NH}_{3}\right)_{6}{ }^{3+}(0.1 \mathrm{M} \mathrm{KCl})$ solutions. Maximum cathodic peak current over time compared to the bare ITO (indicated with a solid line) for (c) $\mathrm{Fe}(\mathrm{CN})_{6}{ }^{3-}$ and $(\mathrm{d}) \mathrm{Ru}\left(\mathrm{NH}_{3}\right)_{6}{ }^{3+}$ solutions. (e) SEM images of the $\mathrm{SiO}_{2}$ MOTF surface over time after electrochemical cycling for $0,15,30,45,60$, and $120 \mathrm{~min}$ at $300 \mathrm{mV} \cdot \mathrm{s}^{-1}$ in a $1 \mathrm{mM} \mathrm{Ru}\left(\mathrm{NH}_{3}\right)_{6}{ }^{3+}$ solution $(0.1 \mathrm{M} \mathrm{KCl})$. 
several hours in the previous experiments. Figure $3 \mathrm{a}, \mathrm{b}$ presents the evolution of voltammograms over time for both electrochemically active probes. The evolution of the thin films integrity can be followed, taking into account the current recorded after each cycle. It is noteworthy to stress that the faradaic current exchange at the electrode is a consequence of the electron transfer from or to the electrochemical probe, which is proportional to the probe concentration in the vicinity of the electrode. ${ }^{30}$ This concentration depends in turn of a complex combination of diffusional transport, preconcentration (through adsorption), and exclusion of the electrochemical probes in the confined mesopore environments. ${ }^{38}$ Therefore, a valid comparison of the thin film dissolution is to compare the current density of the actual film samples $-j_{p}($ film $)$ - with the one of an equivalent ITO bare electrode, $j_{\mathrm{p}}$ (ITO). In a mesoporous electrode, typically $j_{\mathrm{p}}($ film $) / j_{\mathrm{p}}($ ITO $)$ $<1$, due to the tortuosity imparted by the mesopores; ${ }^{39}$ in an electrode that excludes the electrochemical probe, $j_{\mathrm{p}}(\mathrm{film}) /$ $j_{\mathrm{p}}($ ITO $) \rightarrow 0$; in the case of probe preconcentration, $j_{\mathrm{p}}(\mathrm{film}) /$ $j_{\mathrm{p}}($ ITO $) \gg 1$. Finally, if these quantities are equivalent, it is safe to assume that the electrode has dissolved.

In the systems studied, these considerations help to understand the behavior observed. In the case of the negatively charged $\mathrm{Fe}(\mathrm{CN})_{6}{ }^{3-}$, an electrostatic exclusion is expected because the $\mathrm{SiO}_{2}$ walls are negatively charged in the experimental conditions $(\mathrm{pH}>$ point of zero charge, $\mathrm{pzc}=$ $2) .^{40}$ In this case, the absence of a faradaic electrical signal is only possible if Donnan exclusion is into play, and only a nonfaradaic current will flow if the probe cannot reach the underlying electrode. For this probe, an initial nonfaradaic current is registered for $30 \mathrm{~min}$. However, for longer cycling times, a significant and sustained rise in the signal is observed (Figure 3a). This monotonous signal increase can be attributed to the film deterioration caused by film dissolution, which gives place to wall thinning and an increased pore interconnection, in line with the SPR experiments discussed above. This behavior is also consistent with recent findings, in which an increased probe diffusion is critically dependent on the interpore connectivity, and can overcome electrostatic effects, particularly for neck diameters above 2 to $3 \mathrm{~nm} .{ }^{41}$ At the end of the experiment, the registered signal tends to approach the signal registered on the bare substrate, ITO (Figure 3c). This experiment suggests that even for a probe that is electrostatically excluded in mesoporous systems, such as $\mathrm{Fe}(\mathrm{CN})_{6}{ }^{3-}$, silica dissolution can take place in mildly acidic conditions.

In contrast, the electrochemical signal obtained for the positive $\mathrm{Ru}\left(\mathrm{NH}_{3}\right)_{6}{ }^{3+}$ probe sharply increases for the first 20 min, then levels off, and finally diminishes, as seen in Figure 3b,d. In the first few cycles, a signal typical of $\mathrm{Ru}\left(\mathrm{NH}_{3}\right)_{6}{ }^{3+}$ reduction and oxidation attributable to a semi-infinite linear diffusion is observed. Subsequently, other processes that intervene in the electron transfer processes are detected. The first increase is attributed to the appearance of additional anodic and cathodic faradaic peaks, shifted 120 and $50 \mathrm{mV}$ to lower potential, and with a lower peak potential separation. The presence of these peaks can be explained by the electrostatic adsorption of the positively charged probe to the $\mathrm{SiO}_{2}$ walls, which ultimately leads to a second charge transfer mechanism. The $\mathrm{Ru}\left(\mathrm{NH}_{3}\right)_{6}{ }^{3+}$ adsorption was demonstrated by studying the electrochemical signal retrieved after changing the probe solution for pure electrolyte solution $(\mathrm{KCl}$ $0.1 \mathrm{M}$ ) after the signal had reached the maximum current. A typical electrochemical adsorbed response, probably associated to a combination of electrostatic interactions with the surface and counterions, and the electron hopping between adsorbed adjacent $\mathrm{Ru}^{\mathrm{II}} / \mathrm{Ru}^{\mathrm{III}}$ centers can be observed under those conditions for the $\mathrm{Ru}\left(\mathrm{NH}_{3}\right)_{6}{ }^{3+}$ probe, isolating the adsorbed signal from the free one (Figure S1, Supporting Information). ${ }^{42,43}$ Detailed experiments are underway in order to shed light into the probe diffusion processes within the mesopores. ${ }^{44}$ Adsorption of $\mathrm{Ru}\left(\mathrm{NH}_{3}\right)_{6}{ }^{3+}$ on negatively charged matrices has also been reported recently on polyelectrolyte layers and on SAMs modified mesoporous titania thin films. ${ }^{45}$ To study the nature of the adsorption, conditions of high (1 mol dm$\left.{ }^{-3}\right)$ and low $\left(0.1 \mathrm{~mol} \mathrm{dm}^{-3}\right)$ ionic strengths were used (Figure S2). The clear decrease in the probe adsorption with increasing ionic strength also points toward the important role of adsorption, which depends in turn of the double layer. The results for the low ionic strength show that after an important increase of current due to the probe adsorption stage at short times, a decrease of the signal is observed.

For longer times, the CV signal for the positively charged probe markedly decreases and tends to the values registered on the bare ITO, that is, $j_{\mathrm{p}}($ film $) / j_{\mathrm{p}}($ ITO $) \approx 1$ (Figure $3 \mathrm{~d}$ ). The transport regime changes mainly due to a sustained decrease in the current due to probe preconcentration (Figure $3 \mathrm{~b}$ ), which can be attributed to the deterioration of the mesopore system. This was corroborated both visually (Figure S3) and by SEM analysis of the films as a function of the cycling time (Figure $3 e$ ). The optical image shows that the film has been removed in the section exposed to the electrochemical probe. Moreover, SEM images clearly show an increase in pore sizes and the progressive formation of a highly connected wormlike structure. In the same direction, EEP demonstrates that a decrease in the film thickness takes place when the contact time under cycling is increased (Table S1). Hence, the observed behavior of this third stage can be explained as follows: as the silica dissolves, the film specific surface area decreases, and so does the amount of $\mathrm{Ru}\left(\mathrm{NH}_{3}\right)_{6}{ }^{3+}$ compound adsorbed over it and its electrochemical response.

In summary, our results strongly suggest that the ion adsorption combined with the electron transfer processes taking place at the electrode surface assist silica dissolution. This stresses the importance of the role of the double layer formed at the silica mesopore surfaces in the dissolution, which is in coincidence with a recently proposed model that considers the potential difference across the Stern layer as a driving force for dissolution. ${ }^{46}$

In order to confirm the relevance of mesoporosity in the film stability, the adsorption and electrochemical experiments were repeated on control nonmesoporous $\mathrm{SiO}_{2}$ films. No changes in the cyclic voltammetry signal could be observed after $7 \mathrm{~h}$, a period of time much higher than the one used for MOTF (Figure S4). This result demonstrates that the high, accessible specific area is also a key parameter that favors $\mathrm{SiO}_{2}$ dissolution. $^{25}$

Production of Stable Mesoporous Electrodes. Titania MOTF were studied in order to compare the dissolution behavior with their silica counterparts. First, as for the $\mathrm{SiO}_{2}$ case, the behavior of the films under immersion in different solutions in the absence of applied potential was studied. No deterioration of the MOTF structure was observed after $48 \mathrm{~h}$ of the immersion in the $\mathrm{Ru}\left(\mathrm{NH}_{3}\right)_{6}{ }^{3+}$ aqueous solution, as confirmed by SEM and GI-SAXS (Figure $4 \mathrm{~b}, \mathrm{c}$ ). The film thickness is also stable (Table S1) and only a slight difference in the pore size distribution is observed (Figure S5). Thus, 

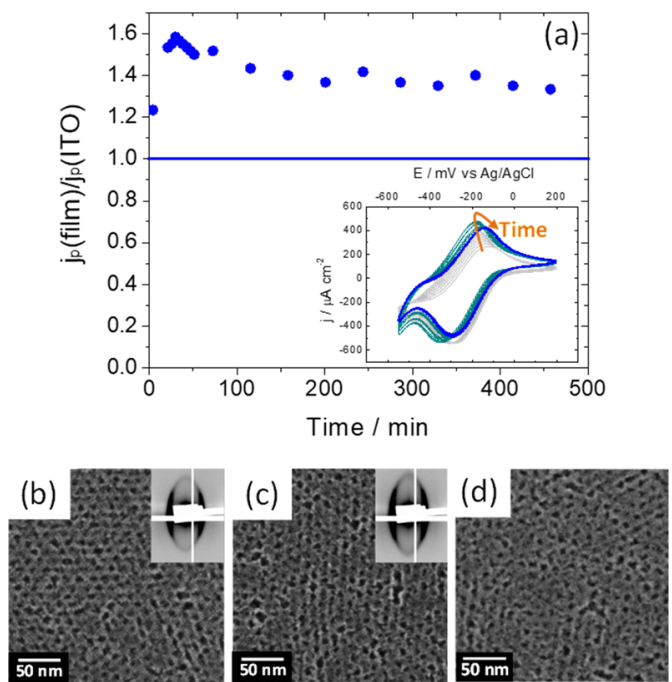

Figure 4. (a) Cathodic peak current of a $1 \mathrm{mM} \mathrm{Ru}\left(\mathrm{NH}_{3}\right)_{6}{ }^{3+}(0.1 \mathrm{M}$ $\mathrm{KCl})$ solution on a $\mathrm{TiO}_{2}$ MOTF along time, compared to the bare ITO (solid line). Inset: voltammograms obtained at $300 \mathrm{mV} \cdot \mathrm{s}^{-1}$ for $\mathrm{TiO}_{2} \mathrm{MOTF}$ at different exposure times. SEM images of the film surface and GI-SAXS patterns (insets) (b) before and (c) after $48 \mathrm{~h}$ of immersion without an applied voltage and (d) SEM image after cycling experiments presented in (a). In all experiments, a $1 \mathrm{mM}$ $\mathrm{Ru}\left(\mathrm{NH}_{3}\right)_{6}{ }^{3+}(0.1 \mathrm{M} \mathrm{KCl})$ solution was used.

these results point toward a very different behavior in comparison with $\mathrm{SiO}_{2}$ samples. In the second step, the behavior of titania films upon exposure to electrochemical cycling in aqueous media was studied. Figure $4 \mathrm{a}$ shows the electrochemical response of the films immersed in a $1 \mathrm{mM}$ $\mathrm{Ru}\left(\mathrm{NH}_{3}\right)_{6}{ }^{3+}(0.1 \mathrm{M} \mathrm{KCl})$ solution for $7.5 \mathrm{~h}$. During the first cycles, the electrochemical signal increases markedly due to the current transported by the probe diffusion and the transport due to the adsorbed $\mathrm{Ru}\left(\mathrm{NH}_{3}\right)_{6}{ }^{3+}$ onto the $\mathrm{TiO}_{2}$ walls, a behavior similar to the case of $\mathrm{SiO}_{2}$. After several cycles, it is clearly seen that the electrochemical response remains almost constant during the experiment and no signs of the film's deterioration is observed (see the SEM image in Figure 4d). When exposed to a $1 \mathrm{mM} \mathrm{Fe}(\mathrm{CN})_{6}{ }^{3-}(0.1 \mathrm{M} \mathrm{KCl})$ solution, the film resulted unaltered during the same period of time (see Figure S6). Moreover, the changes in porosity and thickness of the mesoporous $\mathrm{TiO}_{2}$ are significantly lower than the ones observed for silica and tend to reach a constant value (Table S1). The combination of all these results indicates that $\mathrm{TiO}_{2}$ MOTF can be used as an alternative to $\mathrm{SiO}_{2}$ MOTF in electrochemical applications that require long-term stability, such as permselective sensors, selective electrodes, or separation membranes for fuel cells or solar cells.

However, regardless of the better $\mathrm{TiO}_{2}$ performance for long-term devices, its physical, optical, and chemical properties are considerably different compared to $\mathrm{SiO}_{2}$. Therefore, if properties similar to silica (i.e., transparency, low refractive index, and/or lack of photoresponse), are needed for the desired applications, the addition of a small amount of $\mathrm{ZrO}_{2}$ to $\mathrm{SiO}_{2}$ seems to be a plausible and convenient alternative, as it has been proved to increase stability while retaining similar properties. Mixed oxides such as $\mathrm{Si}-\mathrm{Al}^{31}$ and $\mathrm{Si}-\mathrm{Zr}^{23,29}$ have been proved to present an enhanced aqueous stability,
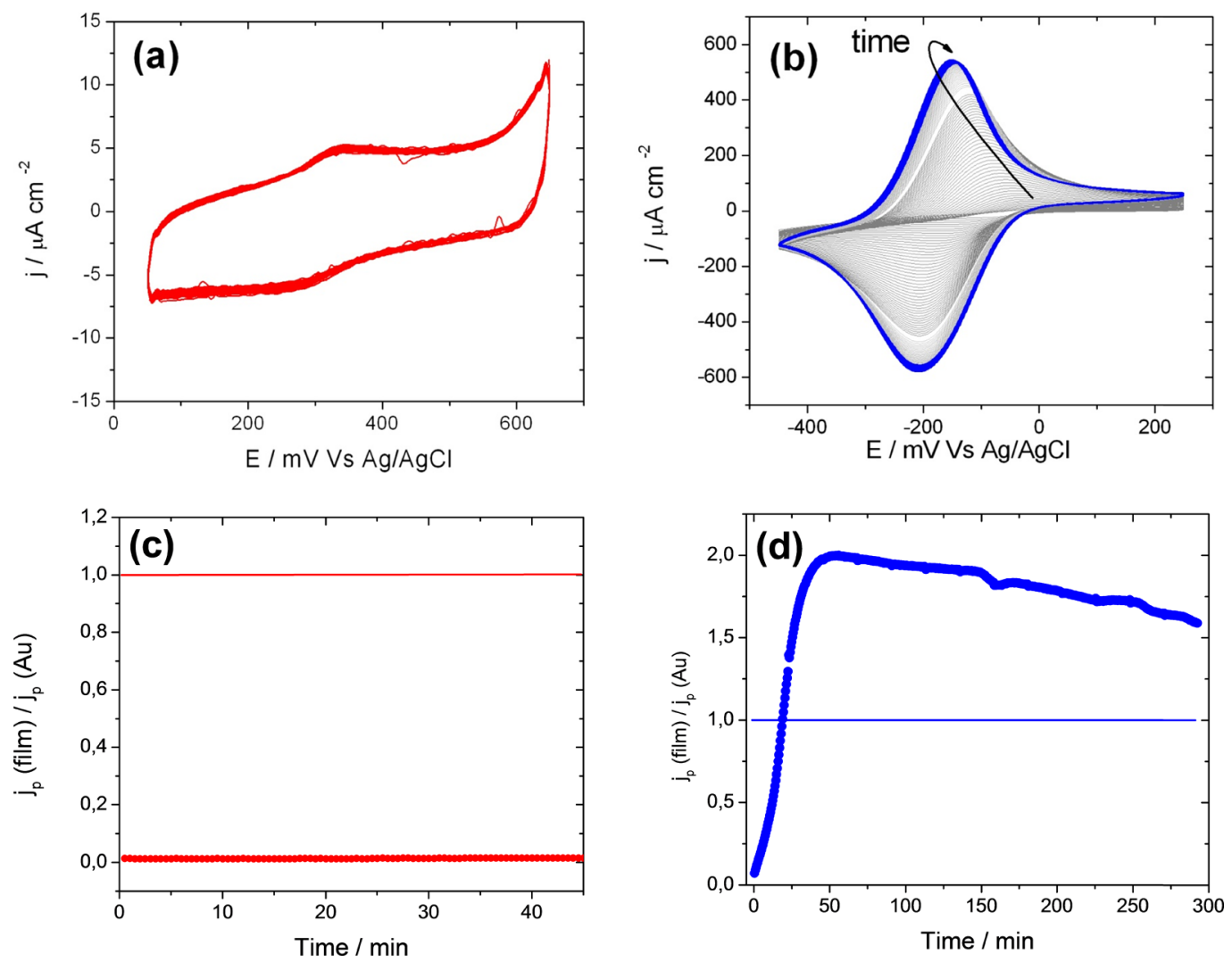

Figure 5. Voltammograms obtained at a scan rate of $50 \mathrm{mV} \mathrm{s}^{-1}$ for the $\mathrm{Si}_{0.9} \mathrm{Zr}_{0.1} \mathrm{O}_{2}$ MOTF coated electrode in (a) $1 \mathrm{mM} \mathrm{Fe}(\mathrm{CN})_{6}^{3-}(0.1 \mathrm{M} \mathrm{KCl})$ and (b) $1 \mathrm{mM} \mathrm{Ru}\left(\mathrm{NH}_{3}\right)_{6}{ }^{3+}(0.1 \mathrm{M} \mathrm{KCl})$ solutions. Ratio of the cathodic peak obtained on the $\mathrm{Si}_{0.9} \mathrm{Zr}_{0.1} \mathrm{O}_{2}$ MOTF coated electrode to the one obtained on the bare electrode for $(\mathrm{c}) \mathrm{Fe}(\mathrm{CN})_{6}{ }^{3-}(0.1 \mathrm{M} \mathrm{KCl})$ and $(\mathrm{d}) \mathrm{Ru}\left(\mathrm{NH}_{3}\right)_{6}{ }^{3+}(0.1 \mathrm{M} \mathrm{KCl})$ solutions. 
particularly in alkaline media. Therefore, $\mathrm{Si}_{0.9} \mathrm{Zr}_{0.1} \mathrm{O}_{2}$ MOTF were prepared and their chemical stability was assessed under electrochemical cycling. SEM images (Figure S7a) showed that $\mathrm{Si}_{0.9} \mathrm{Zr}_{0.1} \mathrm{O}_{2}$ MOTF present a pore structure similar to the one obtained for silica films. On the other hand, the stability of $\mathrm{Si}_{0.9} \mathrm{Zr}_{0.1} \mathrm{O}_{2}$ MOTF under electrochemical cycling in the presence of either $\mathrm{Fe}(\mathrm{CN})_{6}{ }^{4-}$ or $\mathrm{Ru}\left(\mathrm{NH}_{3}\right)_{6}{ }^{3+}$ is considerably increased with respect to $\mathrm{SiO}_{2}$ MOTF. From the cyclic voltammograms shown in Figure 5, a decrease of the dissolution rate by one order of magnitude can be estimated, while the permselective properties and preconcentration behavior observed in $\mathrm{SiO}_{2}$ MOTF are preserved. Moreover, the pore array is almost unmodified after cycling in $\mathrm{Ru}\left(\mathrm{NH}_{3}\right)_{6}{ }^{3+}$, as demonstrated by SEM measurements (Figure $\mathrm{S} 7 \mathrm{~b})$.

\section{CONCLUSIONS}

In summary, we have demonstrated that mesoporous $\mathrm{SiO}_{2}$ electrodes are prone to significant dissolution even in mildly acidic media. The dissolution process, attributed to hydroxyl $(\mathrm{Si}-\mathrm{OH})$ formation that results in breaking of the polymeric gel structure, is affected by several variables. In the first place, the high surface area of the porous structure is crucial; only in the case of mesoporous $\mathrm{SiO}_{2}$, the degradation of the matrix is observed indicating that the exposed high surface strongly determines the reactivity of the oxide. For the case of $\mathrm{SiO}_{2}$ MOTF, when no voltage is applied, the films are dissolved within the order of days, while the dissolution rate increases to the order of hours under electrochemical cycling. Regarding electrochemical probes effect, the presence of $\mathrm{Ru}\left(\mathrm{NH}_{3}\right)_{6}^{3+}$ increases the dissolution rate when compared to $\mathrm{Fe}(\mathrm{CN})_{6}{ }^{3-}$, whether the potential is applied or not. Hence, the adsorption and preconcentration of $\mathrm{Ru}\left(\mathrm{NH}_{3}\right)_{6}{ }^{3+}$ on the silica surface in the mesopore confinement seem to be crucial in the process of dissolution. This enhancement can be directly attributed to the ability of the positive probes to adsorb onto the negatively charged $\mathrm{SiO}_{2}$ surface and assist, through complexation, to dissolve the oxide. Regarding the effect of $\mathrm{pH}$, acidic solutions have shown to diminish but not to prevent the dissolution process under the studied conditions. The increase of the ionic strength, on the other hand, was proved to significantly increase dissolution and should be carefully taken into account when designing experiments. ${ }^{37}$ Not only hydroxide ions have been observed to catalyze silica dissolution, but other anions such as chloride proved to have similar behavior although not widely recognized. ${ }^{31}$ Moreover, the chemical composition of the oxide is also a key parameter in the same conditions that give rise to $\mathrm{SiO}_{2}$ dissolution, as dissolution is significantly arrested in $\mathrm{TiO}_{2}$ and $\mathrm{Zr}(\mathrm{IV})$-substituted silica $\left(\mathrm{Si}_{0.9} \mathrm{Zr}_{0.1} \mathrm{O}_{2}\right)$ films. As dissolution is partially dictated by the electric charge of the oxide, which shows minimum solubility around its pzc, ${ }^{40}$ modifying it by changing the oxide characteristics has a clear effect over its chemical stability.

The results presented here demonstrated that the integrity of $\mathrm{SiO}_{2}$ MOTF electrodes is much more sensitive to external conditions than it has been previously thought or reported. Using a palette of techniques, a more accurate insight into the parameters that affect the dissolution process has been given. According to the presented results, the more relevant aspects that affect $\mathrm{SiO}_{2}$ MOTF electrodes chemical stability are: (i) high specific area due to mesoporosity, (ii) high ionic strength, (iii) electrochemical cycling and (iv) attractive interaction between the electrochemical probe and silica walls.
This basic study has demonstrated that the time scale of the material dissolution, ranging from hours to days, a fact that is especially relevant for its applications as permselective sensors, drug delivery devices, separation membranes, or its incorporation in prosthetics. When long exposures to aqueous media or electrochemical cycling are required (as in the case of reusable electrochemical sensors), the use of $\mathrm{SiO}_{2} \mathrm{MOTF}$ is not recommended because its dissolution occurs in very short times. However, we demonstrated that for long-term operation, $\mathrm{TiO}_{2}$ or $\mathrm{Si}_{0.9} \mathrm{Zr}_{0.1} \mathrm{O}_{2}$ MOTF can be an adequate alternative, as these oxides are more stable in aqueous media even under electrochemical cycling.

\section{ASSOCIATED CONTENT}

\section{Supporting Information}

The Supporting Information is available free of charge on the ACS Publications website at DOI: 10.1021/acs.langmuir.9b00224.

Film thicknesses, voltammograms, peak current, pore and neck size distributions, peak current density, and SEM image of $\mathrm{Si}_{0.9} \mathrm{Zr}_{0.1} \mathrm{O}_{2}$ MOTF surface over gold electrode (PDF)

\section{AUTHOR INFORMATION}

\section{Corresponding Author}

*E-mail: galo.soler.illia@gmail.com; gsoler-illia@unsam.edu.ar. ORCID

Omar Azzaroni: 0000-0002-5098-0612

Paula C. Angelomé: 0000-0002-4402-5045

Galo J. A. A. Soler-Illia: 0000-0001-9984-3806

Notes

The authors declare no competing financial interest.

\section{ACKNOWLEDGMENTS}

This work has been funded by CONICET (PIP 00044CO) and ANPCyT (PICT 2012-0111, PICT 2012-1848, PICT 2013-0905, PICT 2015-3526, PICT 2015-0351, and PICT2016-1680). The authors acknowledge Dr. M. C. Marchi for her assistance in SEM measurements, Dr. J. Dostalek (AIT, Vienna) for access to SPR, and the CERIC-ERIC consortium for the access to experimental facilities at the ELETTRASincrotrone Trieste and the financial support. S.A. and P.Y.S. acknowledge CONICET for their doctoral fellowship.

\section{REFERENCES}

(1) Serrano, E.; Linares, N.; Garcia-Martinez, J.; Berenguer, J. R.; Luque, R.; Garcia Martinez, J. Cover Picture: Sol-Gel Coordination Chemistry: Building Catalysts from the Bottom-Up / Editorial: From Mesoporous Supports to Mesoporous Catalysts: Introducing Functionality to Mesoporous Materials (ChemCatChem 4/2013). ChemCatChem 2013, 5, 825-825.

(2) Brinker, C. J.; Lu, Y.; Sellinger, A.; Fan, H. Evaporation-Induced Self-Assembly: Nanostructures Made Easy. Adv. Mater. 1999, 11, 579-585.

(3) Wei, J.; Sun, Z.; Luo, W.; Li, Y.; Elzatahry, A. A.; Al-Enizi, A. M.; Deng, Y.; Zhao, D. New Insight into the Synthesis of Large-Pore Ordered Mesoporous Materials. J. Am. Chem. Soc. 2017, 139, 17061713.

(4) Soler-Illia, G. J. A. A.; Azzaroni, O. Multifunctional hybrids by combining ordered mesoporous materials and macromolecular building blocks. Chem. Soc. Rev. 2011, 40, 1107-1150.

(5) Alberti, S.; Soler-Illia, G. J. A. A.; Azzaroni, O. Gated supramolecular chemistry in hybrid mesoporous silica nanoarchitec- 
tures: controlled delivery and molecular transport in response to chemical, physical and biological stimuli. Chem. Commun. 2015, 51, 6050-6075.

(6) Cai, K.; Bossert, J.; Jandt, K. D. Does the nanometre scale topography of titanium influence protein adsorption and cell proliferation? Colloids Surf., B 2006, 49, 136-144.

(7) Abu Samah, Z.; Blaine, C. B.; Noel, C. M.; Cyrus, R. S. Nanostructured $\mathrm{TiO}_{2}$ thin films as porous cellular interfaces. Nanotechnology 2005, 17, 531 .

(8) Soler-Illia, G. J. A. A.; Angelomé, P. C.; Fuertes, M. C.; Grosso, D.; Boissière, C. Critical Aspects in the Production of Periodically Ordered Mesoporous Titania Thin Films. Nanoscale 2012, 4, 25492566.

(9) Florek, J.; Caillard, R.; Kleitz, F. Evaluation of mesoporous silica nanoparticles for oral drug delivery - current status and perspective of MSNs drug carriers. Nanoscale 2017, 9, 15252-15277.

(10) Wang, J.; Ma, Q.; Wang, Y.; Li, Z.; Li, Z.; Yuan, Q. New insights into the structure-performance relationships of mesoporous materials in analytical science. Chem. Soc. Rev. 2018, 47, 8766.

(11) Walcarius, A. Silica-based electrochemical sensors and biosensors: Recent trends. Curr. Opin. Electrochem. 2018, 10, 88-97.

(12) Innocenzi, P.; Malfatti, L. Mesoporous thin films: properties and applications. Chem. Soc. Rev. 2013, 42, 4198-4216.

(13) Innocenzi, P.; Malfatti, L.; Soler-Illia, G. J. A. A. Hierarchical Mesoporous Films: From Self-Assembly to Porosity with Different Length Scales. Chem. Mater. 2011, 23, 2501-2509.

(14) Wagner, T.; Haffer, S.; Weinberger, C.; Klaus, D.; Tiemann, M. Mesoporous materials as gas sensors. Chem. Soc. Rev. 2013, 42, 40364053.

(15) Etienne, M.; Guillemin, Y.; Grosso, D.; Walcarius, A. Electrochemical approaches for the fabrication and/or characterization of pure and hybrid templated mesoporous oxide thin films: a review. Anal. Bioanal. Chem. 2013, 405, 1497-512.

(16) Walcarius, A. Mesoporous Materials-Based Electrochemical Sensors. Electroanalysis 2015, 27, 1303-1340.

(17) López-Puente, V.; Abalde-Cela, S.; Angelomé, P. C.; AlvarezPuebla, R. A.; Liz-Marzán, L. M. Plasmonic Mesoporous Composites as Molecular Sieves for SERS Detection. J. Phys. Chem. Lett. 2013, 4, 2715-2720.

(18) Rafti, M.; Brunsen, A.; Fuertes, M. C.; Azzaroni, O.; Soler-Illia, G. J. A. A. Heterogeneous Catalytic Activity of Platinum Nanoparticles Hosted in Mesoporous Silica Thin Films Modified with Polyelectrolyte Brushes. ACS Appl. Mater. Interfaces 2013, 5, 88338840.

(19) Violi, I. L.; Perez, M. D.; Fuertes, M. C.; Soler-Illia, G. J. d. A. A. Highly ordered, accessible and nanocrystalline mesoporous $\mathrm{TiO}_{2}$ Thin films on transparent conductive substrates. ACS Appl. Mater. Interfaces 2012, 4, 4320-30.

(20) Xu, P.; Chen, C.; Li, X. Mesoporous-silica nanofluidic channels for quick enrichment/extraction of trace pesticide molecules. Sci. Rep. 2015, 5, 17171.

(21) Mercuri, M.; Pierpauli, K. A.; Berli, C. L. A.; Bellino, M. G. An Open Pit Nanofluidic Tool: Localized Chemistry Assisted by Mesoporous Thin Film Infiltration. ACS Appl. Mater. Interfaces 2017, 9, 16679-16684.

(22) Walcarius, A. Mesoporous materials and electrochemistry. Chem. Soc. Rev. 2013, 42, 4098-4140.

(23) Bass, J. D.; Grosso, D.; Boissiere, C.; Belamie, E.; Coradin, T.; Sanchez, C. Stability of Mesoporous Oxide and Mixed Metal Oxide Materials under Biologically Relevant Conditions. Chem. Mater. 2007, $19,4349-4356$.

(24) Phama, A. L.-T.; Sedlaka, D. L.; Doyle, F. M. Dissolution of mesoporous silica supports in aqueous solutions: Implications for mesoporous silica-based water treatment processes. Appl. Catal., B 2012, 126, 258-264.

(25) Braun, K.; Pochert, A.; Beck, M.; Fiedler, R.; Gruber, J.; Lindén, M. Dissolution kinetics of mesoporous silica nanoparticles in different simulated body fluids. J. Sol-Gel Sci. Technol. 2016, 79, 319-327.
(26) Andrini, L.; Angelomé, P. C.; Soler Illia, G. J. A. A.; Requejo, F. G. Understanding the $\mathrm{Zr}$ and $\mathrm{Si}$ interdispersion in $\mathrm{Zr}_{1-\mathrm{x}} \mathrm{Si}_{\mathrm{x}} \mathrm{O}_{2}$ mesoporous thin films by using FTIR and XANES spectroscopy. Dalton Transactions 2016, 45, 9977-9987.

(27) Angelomé, P. C.; Fuertes, M. C.; Soler-Illia, G. J. A. A. Multifunctional, Multilayer, Multiscale: Integrative synthesis of complex Macroporous and mesoporous thin films with spatial separation of porosity and function. Adv. Mater. 2006, 18, 23972402.

(28) Crepaldi, E. L.; Soler-Illia, G. de J. A. A.; Grosso, D.; Cagnol, F.; Ribot, F.; Sánchez, C. Controlled Formation of Highly Organized Mesoporous Titania Thin Films: from Mesostructured Hybrids to Mesoporous Nanoanatase $\mathrm{TiO}_{2}$. J. Am. Chem. Soc. 2003, 125, 97709786.

(29) Soler-Illia, G. J. A. A.; Crepaldi, E. L.; Grosso, D.; Sanchez, C. Designed synthesis of large-pore mesoporous silica-zirconia thin films with high mixing degree and tunable cubic or 2D-hexagonal mesostructure. J. Mater. Chem. 2004, 14, 1879-1886.

(30) Bard, A. J.; Faulkner, L. R. Electrochemical Methods: Fundamentals and Applications; 2nd ed.; Wiley: New York, 2000.

(31) Dunphy, D. R.; Singer, S.; Cook, A. W.; Smarsly, B.; Doshi, D. A.; Brinker, C. J. Aqueous Stability of Mesoporous Silica Films Doped or Grafted with Aluminum Oxide. Langmuir 2003, 19, 10403-10408.

(32) Boissiere, C.; Grosso, D.; Lepoutre, S.; Nicole, L.; Bruneau, A. B.; Sanchez, C. Porosity and Mechanical Properties of Mesoporous Thin Films Assessed by Environmental Ellipsometric Porosimetry. Langmuir 2005, 21, 12362-12371.

(33) Amenitsch, H.; Bernstorff, S.; Kriechbaum, M.; Lombardo, D.; Mio, H.; Rappolt, M.; Laggner, P. Performance and First Results of the ELETTRA High-Flux Beamline for Small-Angle X-ray Scattering. J. Appl. Crystallogr. 1997, 30, 872-876.

(34) Violi, I. L.; Zelcer, A.; Bruno, M. M.; Luca, V.; Soler-Illia, G. J. A. A. Gold Nanoparticles Supported in Zirconia-Ceria Mesoporous Thin Films: A Highly Active Reusable Heterogeneous Nanocatalyst. ACS Appl. Mater. Interfaces 2015, 7, 1114-1121.

(35) Szunerits, S.; Boukherroub, R. Preparation and Characterization of Thin Films of $\mathrm{SiO}_{x}$ on Gold Substrates for Surface Plasmon Resonance Studies. Langmuir 2006, 22, 1660-1663.

(36) Szunerits, S.; Coffinier, Y.; Janel, S.; Boukherroub, R. Stability of the Gold/Silica Thin Film Interface: Electrochemical and Surface Plasmon Resonance Studies. Langmuir 2006, 22, 10716-10722.

(37) Fontecave, T.; Sanchez, C.; Azaïs, T.; Boissière, C. Chemical Modification As a Versatile Tool for Tuning Stability of Silica Based Mesoporous Carriers in Biologically Relevant Conditions. Chem. Mater. 2012, 24, 4326-4336.

(38) Contreras, C. B.; Azzaroni, O.; Soler-Illia, G. J. A. A. Use of Confinement Effects in Mesoporous Materials to Build Tailored Nanoarchitectures. In Reference Module in Materials Science and Materials Engineering; 2018.

(39) Otal, E. H.; Angelomé, P. C.; Bilmes, S. A.; Soler-Illia, G. J. A. A. Functionalized Mesoporous Hybrid Thin Films as Selective Membranes. Adv. Mater. 2006, 18, 934-938.

(40) Kosmulski, M. pH-dependent surface charging and points of zero charge. IV. Update and new approach. J. Colloid Interface Sci. 2009, 337, 439-448.

(41) Angiolini, J. F.; Stortz, M.; Steinberg, P. Y.; Mocskos, E.; Bruno, L.; Soler-Illia, G.; Angelomé, P. C.; Wolosiuk, A.; Levi, V. Diffusion of single dye molecules in hydrated $\mathrm{TiO}_{2}$ mesoporous films. Phys. Chem. Chem. Phys. 2017, 19, 26540-26544.

(42) Fattakhova Rohlfing, D.; Rathouský, J.; Rohlfing, Y.; Bartels, O.; Wark, M. Functionalized Mesoporous Silica Films as a Matrix for Anchoring Electrochemically Active Guests. Langmuir 2005, 21, $11320-11329$.

(43) Vilè, N.; Walcarius, A. Electrochemical response of verticallyaligned, ferrocene-functionalized mesoporous silica films: effect of the supporting electrolyte. Electrochim. Acta 2015, 179, 304-314.

(44) Giménez, G. Fabrication and characterization of electrodes array with a mesoporous thin film coating based on silicon and 
zirconium/silicon oxide. Universidad de Buenos Aires, Buenos Aires, Argentina, 2018.

(45) Taffa, D. H.; Kathiresan, M.; Walder, L.; Seelandt, B.; Wark, M. Pore size and surface charge control in mesoporous $\mathrm{TiO} 2$ using postgrafted SAMs. Phys. Chem. Chem. Phys. 2010, 12, 1473-1482.

(46) Crundwell, F. K. On the Mechanism of the Dissolution of Quartz and Silica in Aqueous Solutions. ACS Omega 2017, 2, 11161127. 